\title{
Influência do nitrogênio e do fósforo na produção do capim-braquiária ${ }^{1}$
}

\author{
Albertí Ferreira Magalhães ${ }^{2}$, Aureliano José Vieira Pires ${ }^{3}$, Gleidson Giordano Pinto \\ de Carvalho ${ }^{4}$, Fabiano Ferreira da Silva ${ }^{3}$, Ronaldo Silva Sousa ${ }^{5}$, Cristina Mattos Veloso ${ }^{3}$ \\ 1 Parte da dissertação de Mestrado em Zootecnia do primeiro autor. Itapetinga, BA, Universidade Estadual do Sudoeste da Bahia, UESB, \\ BA, CEP: 45700-000. \\ 2 Mestre em Zootecnia - MAPA/CEPLAC/EMARC-IT, Rod. Itapetinga/Itororó, km 02, CEP: 45700-000, Itapetinga-Bahia. \\ 3 UESB, Itapetinga, BA. Pesquisador do CNPq. \\ ${ }^{4}$ Doutorando em Zootecnia/UFV, Viçosa, MG. \\ 5 MAPA/CEPLAC/EMARC-IT, Rod. Itapetinga/Itororó, km 02, CEP: 45700-000, Itapetinga-Bahia.
}

RESUMO - Este experimento foi conduzido para avaliar a produção de MS, a relação folha:colmo, o teor de PB e a eficiência de resposta ao nitrogênio da folha e do colmo do capim-braquiária adubado com diferentes doses de nitrogênio e de fósforo durante o verão. Utilizou-se o delineamento experimental inteiramente casualizado, com três repetições, em esquema fatorial $4 \times 3$, composto de quatro doses de nitrogênio $(\mathrm{N})(0,100,200$ e $300 \mathrm{~kg} / \mathrm{ha} / \mathrm{ano})$, utilizando-se o sulfato de amônio, e três doses de $\mathrm{P}_{2} \mathrm{O}_{5}(0,50$ e $100 \mathrm{~kg} / \mathrm{ha} / \mathrm{ano})$, utilizando-se o superfosfato simples. A quantidade de $\mathrm{K}$ aplicada foi de $40 \mathrm{~kg} / \mathrm{ha} / \mathrm{ano}$. Os cortes (a $20 \mathrm{~cm}$ do solo) foram realizados em intervalos de 28 dias, totalizando três cortes durante o experimento. Após cada corte, foi realizada adubação, conforme os tratamentos. A adubação nitrogenada afetou a produção de MS, que apresentou valores máximos de 5.345,6 e 4.857,7 kg/ha para folha e colmo, respectivamente. A relação folha:colmo foi maior $(1,31)$ na dose de $\mathrm{N}$ de $200 \mathrm{~kg} / \mathrm{ha}$, independentemente da dose de fósforo. A adubação nitrogenada teve efeito quadrático sobre o teor de PB das folhas e efeito linear sobre o teor de PB no colmo. A adubação com fósforo, no entanto, não teve efeito sobre essas variáveis. A eficiência de utilização do $\mathrm{N}$ teve efeito quadrático quando utilizadas doses crescentes de N. O ponto de máxima foi obtido com 245,3 kg de N, dose que proporcionou 18,84 kg de $\mathrm{MS} / \mathrm{kg}$ de $\mathrm{N}$.

Palavras-chave: adubação, eficiência de utilização de nitrogênio, forrageira, proteína bruta, relação folha:colmo

\section{Influence of nitrogen and phosphorus on Brachiaria decumbensstapf. production}

\begin{abstract}
This experiment was conducted to evaluate the DM production, leaf:stem ratio, CP content and leaf and stem efficiency response to nitrogen of Brachiaria decumbens Stapf. grass, fertilized with different $\mathrm{N}$ and $\mathrm{P}$ doses during the summer period. A completely randomized experimental design was used, with three replicates in a 4 x 3 factorial arrangement, composed by four $\mathrm{N}$ doses $(0,100,200$ and $300 \mathrm{~kg} / \mathrm{ha} / \mathrm{year})$, using ammonium sulfate, and three $\mathrm{P}_{2} \mathrm{O}_{5}$ doses $(0$, 50 and $100 \mathrm{~kg} / \mathrm{ha} / \mathrm{year}$ ), using super simple phosphate. The $\mathrm{K}$ amount applied was $40 \mathrm{~kg} / \mathrm{ha} / \mathrm{year}$. The cuts (at $20 \mathrm{~cm}$ of the soil) were performed every 28 days, in a total of three cuts during the experiment. After each cut, fertilization was accomplished according to the treatment. $\mathrm{N}$ fertilization affected DM production, that showed maximum values of 5,345.6 and 4,857.7 kg/ha of leaf and stem, respectively. Leaf:stem ratio was greater (1.31) with $200 \mathrm{~kg} / \mathrm{ha} \mathrm{N}$ dose, independent of the phosphorus dose. N fertilization had quadratic effect on CP content of the leaves and linear effect on CP content of the stem. P fertilization, however, had no effect on these variables. The $\mathrm{N}$ efficiency of utilization had quadratic effect when increasing $\mathrm{N}$ doses were used. The point of maximum was $245.3 \mathrm{~kg}$ of $\mathrm{N}$, dose that provided $18.84 \mathrm{~kg}$ of DM/ $\mathrm{kg}$ of N.
\end{abstract}

Key Words: crude protein, fertilization, leaf:stem ratio, roughage, nitrogen utilization efficiency

\section{Introdução}

Baixos índices de produção de carne e leite são observados frequientemente no País. Vários fatores contribuem para isso, entre eles, a baixa fertilidade natural do solo e a reduzida disponibilidade de nutrientes, como fósforo, em decorrência da freqüente exploração. O déficit pluviométrico e sua má distribuição durante o ano também contribuem para esses baixos índices (Fagundes et al., 2005).

Os maiores problemas da exploração da pecuária estão relacionados à deficiência e baixa qualidade das pastagens no período seco do ano prejudicando o desempenho animal. Além da escassez, as pastagens apresentam baixo valor nutritivo, o que resulta em baixa eficiência produtiva e reprodutiva (Yokoyama et al., 1999). Assim, para atingiralta 
produtividade animal, são necessárias adubações e escolha de gramíneas forrageiras com potencial para produção de forragem com bom valor nutritivo (Quadros et al., 2002).

Braz et al. (2002) afirmaram que, além do tipo de solo e da baixa fertilidade, as condições climáticas adversas afetam negativamente a qualidade nutritiva das forrageiras, limitando o consumo de nutrientes e não atendendo às exigências do animal. No estabelecimento de uma pastagem, deve-se dar atenção à adubação fosfatada, cujas doses, para os diferentes sistemas de produção, dependem da disponibilidade de fósforo, que varia conforme a textura do solo e o teor de fósforo remanescente (Cantarutti et al., 1999b).

Fagundes et al. (2005) verificaram que o suprimento de $\mathrm{N}$ no solo normalmente não atende à demanda das gramíneas, porém, quando há adubação nitrogenada, são observadas grandes alterações na taxa de acúmulo de MS da forragem do capim-braquiária ao longo das estações do ano.

A economicidade da exploração de uma pastagem deve ser avaliada quanto à produção animal por hectare, que depende de sua capacidade de suporte e da produção por animal, reflexo do seu valor nutritivo (Paciullo et al., 1998). Portanto, segundo Ribeiro et al. (1999), deve-se conciliar o rendimento forrageiro com o valor nutritivo da planta para obtenção de maior produção animal por unidade de área.

Neste estudo objetivou-se avaliar a produção de MS, a relação folha:colmo, o teor de proteína bruta e a eficiência de resposta do capim Brachiaria decumbens Stapf à adubação com diferentes doses de nitrogênio e de fósforo.

\section{Material e Métodos}

O experimento foi conduzido na Escola Média de Agropecuária Regional da CEPLAC (EMARC) e no Laboratório de Forragicultura e Pastagem da Universidade Estadual do Sudoeste da Bahia, UESB, na cidade de Itapetinga, região Centro-Sul da Bahia, localizada a 150 18' 14" de latitude sul e $40^{\circ} 12^{\prime} 10^{\prime \prime}$ de longitude oeste e altitude de $268 \mathrm{~m}$.

O clima é do tipo "Cw" mesotérmico úmido e subúmido, quente e com inverno seco, pela classificação de Köppen. O período de verão é quente e chuvoso (Tabela 1) e abrange os meses de outubro a março, enquanto o período frio é seco, sem chuvas, e inclui os meses de abril a setembro. $\mathrm{O}$ experimento foi conduzido em uma área de pastagem de Brachiaria decumbens já estabelecida. Utilizou-se um piquete do módulo das vacas mestiças (Gir $\times$ Holandês) em lactação com tamanho de 0,50 ha, em uma área totalmente plana. Em 1997, verificou-se a formação das pastagens com sementes de Brachiaria decumbens. No preparo do solo para implantação da pastagem, foram feitas as práticas de aração, gradagem e adubação de estabelecimento. O plantio foi feito em linha e depois cruzado, para formação de um bom estande de plantas na área, utilizando-se sementes de Brachiaria decumbens e uma plantadeira de grãos para essa prática. O fósforo (superfosfato simples) foi aplicado no plantio junto com as sementes. Até o início da coleta da amostra de solo para análise, havia vacas pastejando nos piquetes. Esses animais foram mantidos em cada um dos piquetes durante três dias utilizando-se período de descanso de 28 dias. Um piquete foi isolado e uma área foi aleatoriamente escolhida (depois de cercada, media $18 \times 35 \mathrm{~m}$ ). Dentro, foram feitas as parcelas experimentais, sorteadas aleatoriamente. Durante o período experimental, as vacas não tiveram acesso ao piquete.

Em dezembro de 2001, foram coletadas (à profundidade de 0 a $20 \mathrm{~cm}$ ) amostras simples de solo para formação de uma amostra composta (Cantarutti et al., 1999a). Após análise química, foram observadas as seguintes características do solo: $\mathrm{pH}$ em água $=6,1 ; \mathrm{P}$ disponível $=4,0 \mathrm{mg} / \mathrm{dm}^{3} ; \mathrm{K}=0,15$ $\mathrm{cmol}_{\mathrm{c}} / \mathrm{dm}^{3} ; \mathrm{Ca}$ e $\mathrm{Mg}=5,4$ e $1,5 \mathrm{cmol}_{\mathrm{c}} / \mathrm{dm}^{3} ; \mathrm{Al}$ e $\mathrm{H}=0,0$ e 2,4 $\mathrm{cmol}_{\mathrm{c}} / \mathrm{dm}^{3}$, respectivamente. Como características físicas, o solo apresentou textura franco-argilo-arenosa, com $25 \%$ de argila, $28 \%$ de areia grossa, $40 \%$ de areia fina e $7 \%$ de silte.

De acordo com a análise do solo, não houve necessidade de correção com calcário. Realizou-se apenas uma adubação potássica com $40 \mathrm{~kg} / \mathrm{ha} /$ ano utilizando-se o cloreto de potássio para uniformização das parcelas de acordo com o sistema de exploração adotado em pastagem com nível tecnológico médio (Cantarutti et al., 1999b). Junto com o potássio, aplicou-se o fósforo, de uma só vez, no corte de uniformização. O nitrogênio foi parcelado em três vezes, $1 / 3$ em cada período.

Utilizou-se o delineamento inteiramente casualisado, com três repetições, em um esquema fatorial $4 \times 3$, composto de quatro doses de nitrogênio (0, 100, 200 e $300 \mathrm{~kg} / \mathrm{ha} / \mathrm{ano})$, na forma de sulfato de amônio, e de três doses de fósforo $(0,50$ e $100 \mathrm{~kg} / \mathrm{ha} / \mathrm{ano})$, na forma de superfosfato simples, totalizando 12 tratamentos e 36 parcelas experimentais medindo cada uma $2 \times 4 \mathrm{~m}$.

Os cortes foram realizados a $20 \mathrm{~cm}$ do solo, em intervalos de 28 dias (três corte no total), utilizando-se uma tesoura de poda de jardim. O primeiro corte foi feito em janeiro de 2002, ao início do experimento, para uniformização de todas as parcelas, e o último, em 20 de abril de 2002. As parcelas apresentaram distância de $0,5 \mathrm{~cm}$ entre bordaduras e foram mantidas sob freqüente capina. Após os cortes, procedeu-se à adubação das parcelas. As aplicações de nitrogênio foram feitas em três épocas, todas no período chuvoso (janeiro, fevereiro e março). 
O material coletado em cada parcela foi pesado e homogeneizado para retirada de amostras representativas para separação das folhas e dos colmos, utilizados em quantidade padrão (100 g de folha) para análise posterior. Os colmos que sobraram da quantidade das folhas separadas foram pesados e ensacados para posterior análise, juntamente com as folhas.Foram avaliadas as produções totais de matéria seca (MS) de folhas e colmos e a relação folha/ colmo e analisadas as concentrações de PB, conforme procedimento descrito por Silva \& Queiroz (2002), efetuando-se o estudo da eficiência de resposta ao nitrogênio $(\mathrm{kg}$ de MS/kg de N) aplicado.

Para escolha do modelo mais adequado, foram testados alguns modelos de regressão linear múltipla. Aplicou-se o teste $\mathrm{t}$ a $5 \%$ de probabilidade e obteve-se o coeficiente de determinação utilizando-se o programa computacional SAEG - Sistema de Análises Estatísticas e Genéticas da Universidade Federal de Viçosa (UFV) (Ribeiro Jr., 2001).

\section{Resultados e Discussão}

Houve diminuição da precipitação no fim do período da avaliação (Tabela 1), fato previsto, em virtude das proximidades do outono e da diminuição das chuvas na região.

A variação de temperatura média entre as semanas e durante os cortes foram de 23,9 a $26,7^{\circ} \mathrm{C}$ durante o período experimental e permitiu crescimento das forrageiras melhor que em outros períodos do ano.
A precipitação acumulada foi de $316,7 \mathrm{~mm}$ e a evaporação, de 490,4 mm, o que comprova a ocorrência de um déficit hídrico no período, que pode ter influenciado diretamente a qualidade e o rendimento das forrageiras.

Não houve efeito da interação doses de fósforo $\times$ doses de nitrogênio sobre a produção de MS, em kg/ha. Verificaram-se efeito linear $(\mathrm{P}<0,05)$ das doses de nitrogênio sobre a produção de MS da folha eefeito quadrático sobre a produção de MS do colmo.

A produção de MS refere-se ao somatório dos três cortes (Tabela 2) do capim Brachiaria decumbense não foi influenciada $(\mathrm{P}>0,05)$ pelas doses de fósforo. No entanto, aumentou de acordo com as doses de nitrogênio (0, 100, 200 e $300 \mathrm{~kg} / \mathrm{ha}$ ). Esses resultados confirmam o observado por Rossi et al. (1997) e Fagundes et al. (2005), que, ao utilizarem doses de nitrogênio de até $300 \mathrm{~kg} / \mathrm{ha}$, também verificaram aumento na produção de MS. A adubação com nitrogênio contribui de forma significativa para a produção de forrageiras tropicais. Na literatura, verifica-se que, em períodos favoráveis como o verão, quando se dispõe de temperatura e pluviosidade, o capim-braquiária apresenta melhor rendimento forrageiro.

Filgueiras et al. (1997), ao avaliarem o rendimento médio de MS de capim-braquiária aos 28 dias de corte, encontraram valores de 3.905 e $3.209 \mathrm{~kg} / \mathrm{ha}$ na folha e no colmo, respectivamente. Rassini (2004) verificou que o capimbraquiária, quando não irrigado, apresentou produção de MS de 16,1 t/ha e, quando irrigado, 24,3 t/ha, superando

Tabela 1 - Temperaturas ( $\mathrm{T}^{\mathrm{a}}$ ) mínimas, máximas e médias, precipitação e evaporação durante o período de janeiro a abril de 2002 Table 1 - Minimum, maximum and mean temperatures (Ta), rainfall and evaporation during the experimental period, from January to April of 2002

\begin{tabular}{|c|c|c|c|c|c|c|}
\hline $\begin{array}{l}\text { Corte } \\
\text { Cut }\end{array}$ & $\begin{array}{c}\text { Semana } \\
\text { Week }\end{array}$ & $\begin{array}{l}\mathrm{T}^{\mathrm{a}} \text { mínima }\left({ }^{\circ} \mathrm{C}\right) \\
\text { Minimum } T^{a}\left({ }^{\circ} \mathrm{C}\right)\end{array}$ & $\begin{array}{l}\mathrm{T}^{\mathrm{a}} \text { máxima }\left({ }^{\circ} \mathrm{C}\right) \\
\text { Maximum } T^{a}\left({ }^{\circ} \mathrm{C}\right)\end{array}$ & $\begin{array}{c}\mathrm{T}^{\mathrm{a}} \text { média }\left({ }^{\circ} \mathrm{C}\right) \\
\text { Mean } T^{a}\left({ }^{\circ} \mathrm{C}\right)\end{array}$ & $\begin{array}{c}\text { Precipitação (mm/semana) } \\
\text { Rainfall (mm/week) }\end{array}$ & $\begin{array}{c}\text { Evaporação }(\mathrm{mm} / \mathrm{semana}) \\
\text { Evaporation }(\mathrm{mm} / \text { week })\end{array}$ \\
\hline \multirow[t]{4}{*}{$1 \stackrel{0}{0}$} & $1 \underline{\mathrm{a}}$ & 20,0 & 32,1 & 26,7 & 0,0 & 52,5 \\
\hline & $2 \underline{\mathrm{a}}$ & 21,3 & 29,1 & 24,5 & 191,7 & 33,1 \\
\hline & $3 \underline{a}$ & 20,3 & 30,7 & 25,0 & 1,4 & 45,0 \\
\hline & $4 \underline{a}$ & 21,1 & 32,8 & 26,2 & 0,0 & 52,5 \\
\hline \multirow[t]{4}{*}{$2^{\underline{\mathrm{o}}}$} & $1 \underline{\mathrm{a}}$ & 20,8 & 31,9 & 25,8 & 0,0 & 50,3 \\
\hline & $2 \underline{a}$ & 20,6 & 30,0 & 24,3 & 32,9 & 33,9 \\
\hline & $3 \underline{a}$ & 21,1 & 29,9 & 24,8 & 31,3 & 33,1 \\
\hline & $4 \underline{a}$ & 21,2 & 31,4 & 25,7 & 10,0 & 40,8 \\
\hline \multirow[t]{6}{*}{$3 \underline{0}$} & $1 \underline{\mathrm{a}}$ & 20,3 & 30,9 & 24,9 & 13,7 & 41,1 \\
\hline & $2 \underline{a}$ & 19,7 & 29,5 & 23,9 & 30,9 & 32,5 \\
\hline & $3 \underline{a}$ & 20,3 & 30,7 & 24,8 & 0,0 & 39,1 \\
\hline & $4^{\mathrm{a}}$ & 20,1 & 30,0 & 24,9 & 4,8 & 36,5 \\
\hline & Total & & & & 316,73 & 490,4 \\
\hline & Média & 20,6 & 30,8 & 25,1 & 26,4 & 40,9 \\
\hline
\end{tabular}

${ }^{1}$ Medida feita em tanque "classe A" (Measure made in "class $A$ " tank).

* Fonte (Source): CEPLAC/CEPEC/CLIMATOLOGIA/EMARC-IT.

CEPLAC - Comissão Executiva do Plano da Lavoura Cacaueira - Ilhéus-Bahia.

CEPEC - Centro de Pesquisa do Cacau - Ilhéus-Bahia.

CLIMATOLOGIA - Seção Climatológica do CEPEC que coleta informações sobre o tempo na região.

EMARC-IT - Escola Média de Agropecuária Regional da CEPLAC - Itapetinga-Bahia. 
outras forrageiras comoBrachiaria brizantha cv. Marandu e Cynodon dactylon cv. Coastcross.

Andrade et al. (1996) verificaram em ensaios que os resultados da adubação com e sem nitrogênio, em Brachiaria ruziziensis, renderam produções de MS em torno de 19.085 e $4.559 \mathrm{~kg} / \mathrm{ha}$, respectivamente. Botrel et al. (1999) verificaram que Brachiaria decumbens apresentou potencial forrageiro e produziu $11.425 \mathrm{~kg}$ de MS/ha/ano no período das chuvas.

A produção de colmos aos 28 dias foi semelhante à de folhas. Portanto, o corte em idades superiores, dependendo da época do ano, poderia ocasionar aumento da proporção de colmos em relação à de folhas, em virtude do alongamento das plantas face às condições climáticas. Aroeira et al. (2005) verificaram que $B$. decumbens é uma espécie de maior eficiência fotossintética em condições tropicais e de melhor adaptação a solos de baixa fertilidade e que proporciona maiores respostas produtivas nos meses de precipitações e temperaturas mais altas.

Não houve interação significativa de doses de nitrogênio $\times$ doses de fósforo sobre a relação folha:colmo (Tabela 3). Verificou-se efeito quadrático $(\mathrm{P}<0,05)$ apenas das doses de $\mathrm{N}$, pois, quando não foi utilizado nenhuma dose de $\mathrm{N}$, a relação folha:colmo foi igual a 1 . A relação folha:colmo tendeu a diminuir nas doses de $\mathrm{N}$ superiores a $200 \mathrm{~kg} / \mathrm{ha}$, representando baixa relação folha:colmo. A eficiência de conversão do nitrogênio até a dose de $200 \mathrm{~kg} / \mathrm{h}$ a representa ganho da forrageira, o que não foi observado na dose de $300 \mathrm{~kg} / \mathrm{ha}$, a qual promoveu diminuição desta relação. Alta relação folha:colmo representa forragem de elevado teor de proteína e melhor ganho animal. Paciullo et al. (1998) afirmaram que a contribuição do percentual de lâminas foliares em relação ao colmo na produção total de forragem tem importância acentuada, pois determina o valor nutritivo da forragem. Para obtenção de boa relação folha:colmo, é necessário que a pastagem seja bem manejada para apresentar boa rebrota e produzir bom volume de forragem. Além disso, essa forragem deve ser constituída principalmente de folhas, pois nas folhas são encontrados maiores teores de PB e de outros nutrientes (Zimmer et al., 1995). Na dose de $300 \mathrm{~kg}$ de N/ha, a produção de folhas reduziu, evidenciando aumento no acúmulo de colmo, possivelmente em virtude do elongamento do colmo, fato também observado por Paciullo et al. (1998).

Esses fatos, independentemente da adubação, podem ser atribuídos ao intervalo de cortes (28 dias), à época do ano e ao clima, o que permitiu maior crescimento da planta e, conseqüentemente, maior produção de folhas. Paciullo et al. (2003) obtiveram para relação folha:colmo valores de 0,71 a 0,95 para a braquiária em monocultivo e de 0,54 a 0,68 para a braquiária consorciada com Stylosanthes guianensis. Esses valores foram inferiores aos encontrados neste trabalho.

A interação doses de fósforo $\times$ doses de nitrogênio não influenciou $(\mathrm{P}>0,05)$ o teor de $\mathrm{PB}$ da forragem, no entanto,

Tabela 2 - Produção de MS da folha e do colmo (soma de três cortes) de Brachiaria decumbens adubada com diferentes doses de fósforo e de nitrogênio

Table 2 - Leaf and stem DM production (sum of three cuts) of Brachiaria decumbens fertilized with different phosphorus and nitrogen doses

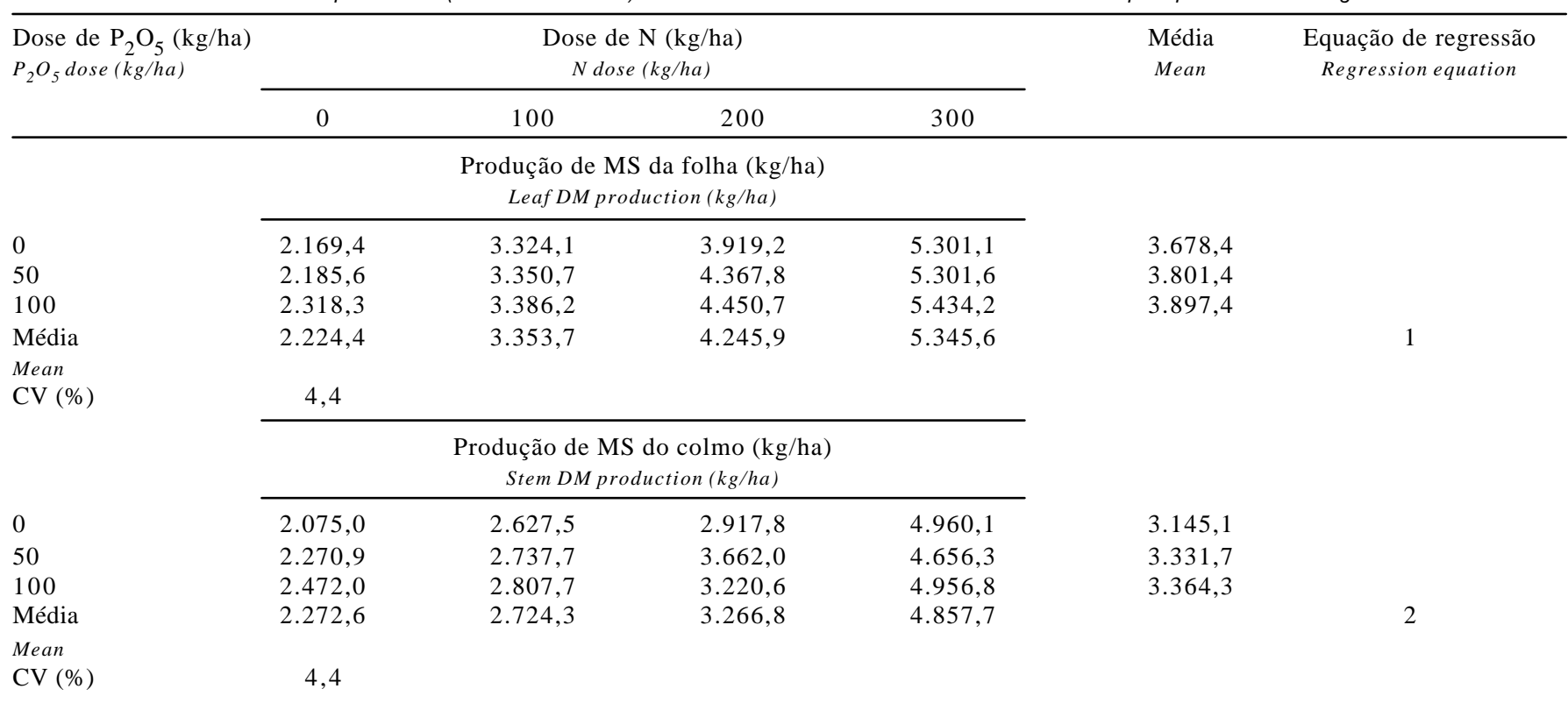

$1-\hat{\mathrm{Y}}=2254,03+10,2559^{* *} \times \mathrm{N}, \mathrm{R}^{2}=0,98$

$2-\hat{\mathrm{Y}}=2320,50-0,246347 \times \mathrm{N}+0,0284807^{\star *} \times \mathrm{N}^{2}, \mathrm{R}^{2}=0,90$.

*, ${ }^{* *}(P<0,05)$ e $(P<0,01)$. 
Tabela 3 - Relação folha:colmo (soma de três cortes) de Brachiaria decumbens adubada com diferentes doses de fósforo e nitrogênio

Table 3 - Leaf stem ratio (sum of three cuts) of Brachiaria decumbens fertilized with different phosphorus and nitrogen doses

\begin{tabular}{lcccc}
\hline $\begin{array}{l}\text { Dose de } \mathrm{P}_{2} \mathrm{O}_{5}(\mathrm{~kg} / \mathrm{ha}) \\
P_{2} \mathrm{O}_{5} \text { dose }(\mathrm{kg} / \mathrm{ha})\end{array}$ & $\begin{array}{c}\text { Dose de } \mathrm{N}(\mathrm{kg} / \mathrm{ha}) \\
N \text { dose }(\mathrm{kg} / \mathrm{ha})\end{array}$ & $\begin{array}{c}\text { Média } \\
\text { Mean }\end{array}$ & $\begin{array}{c}\text { Equação de regressão } \\
\text { Regression equation }\end{array}$ \\
\cline { 2 - 5 } & 0 & 100 & 200 & 300
\end{tabular}

\begin{tabular}{lccrrr}
\hline \multicolumn{5}{c}{$\begin{array}{c}\text { Relação folha:colmo } \\
\text { Leaf:stem ratio }\end{array}$} & 1,19 \\
0 & 1,27 & 1,35 & 1,07 & 1,14 \\
50 & 1,06 & 1,22 & 1,21 & 1,14 & 1,16 \\
Média & 1,00 & 1,21 & 1,38 & 1,10 & 1 \\
Mean & 1,94 & 1,23 & 1,31 & 1,10 & \\
CV $(\%)$ & 1,00 & & & & \\
\hline
\end{tabular}

$1-\hat{Y}=0,994804853+0,003703008^{* *} x N-0,0000110783^{* *} x N^{2}, R^{2}=0,84$

${ }^{*},{ }^{* *}(\mathrm{P}<0,05)$ e $(\mathrm{P}<0,01)$.

teve efeito quadrático $(\mathrm{P}<0,05)$ sobre o teor de $\mathrm{PB}$ da folha. As doses de $\mathrm{N}$ tiveram efeito linear $(\mathrm{P}<0,05)$ sobre o teor de $\mathrm{PB}$ do colmo, que, no entanto, não foi influenciado $(\mathrm{P}>0,05)$ pelas doses de fósforo (Tabela 4).

De modo geral, os teores de PB, tanto na folha quanto no colmo, aumentaram de acordo com as doses de nitrogênio. Ruggieri et al. (1995), ao avaliarem doses de adubação nitrogenada e regimes de corte em Brachiaria brizantha, verificaram que, com 28 dias de intervalo de corte, os valores de PB foram de 13,5; 16,3 e 17,3\% para as doses de nitrogênio de 0,33 e $66 \mathrm{~kg} / \mathrm{ha}$, respectivamente. Esses autores observaram também que a tendência geral foi de aumento no teor de PB das folhas com o aumento da dose de nitrogênio. Quando comparadas as doses de 0 e $100 \mathrm{~kg}$ de N/ha, verificou-se incremento médio de 22,5\% de PB na folha. Entretanto, quando comparadas as demais doses sem o controle, verificou-se variação de 8 a $17 \%$.

Os elevados teores de PB em todas as frações da planta nos níveis mais altos de adubação indicam que boa quantidade de nitrogênio ficou nos tecidos das plantas, possivelmente na forma inorgânica. Essa concentração pode ser atribuída à maior proporção de folhas na planta, mas, neste caso, nas doses de $300 \mathrm{~kg}$ de N/ha, as proporções de folhas foram menores que as de colmos nas doses de $200 \mathrm{~kg}$ de N/ha.

$\mathrm{O}$ valor de $\mathrm{PB}$ na folha foi maior que o descrito por Euclides et al. (1998), que encontraram valores médios de $8 \%$ de PB para folha da Brachiaria decumbens no verão. Resultados próximos aos observados neste trabalho foram relatados por Andrade et al. (1996), que estudaram o efeito da adubação nitrogenada e potássica na composição de forragem de Brachiaria ruziziensis. Sem aporte de N, observaram valores médios de $7,7 \%$ de PB na MS, enquanto, sem adubação com $100 \mathrm{~kg}$ de N/ha, o valor encontrado foi de $12,39 \%$ de PB. Resultados diferentes foram obtidos por Paciullo et al. (2001), que, em Brachiaria decumbens, encontraram valores de 16,0 e 13,2\% de PB nas folhas com 20 dias de corte no verão e no outono, respectivamente. Nesses mesmos períodos, os valores encontrados para o colmo foram 3,6 e 8,6\% de PB, respectivamente.

Sarda et al. (1998) encontraram valores médios de 4,5 a 6,3\% de PB para o colmo da Brachiaria decumbens e Gomide et al. (2001), em pastagens de Brachiaria decumbensmanejada sob duas ofertas diárias de forragem (4 e $8 \%$ do peso vivo), encontraram na folha valores médios de 12,4 e $14,3 \%$ de $\mathrm{PB}$, respectivamente. Botrel et al. (1999) e Botrel et al. (2002) verificaram em Brachiaria decumbens valores de 10,4 e 5,8\% e 7,0 e 5,4\% de PB nos períodos chuvoso e seco, respectivamente.

Paciullo et al. (2003) determinaram as características produtivas e qualitativas de pastagens de braquiária e verificaram valores de 6,6 e 8,6\% de PB para o meses de

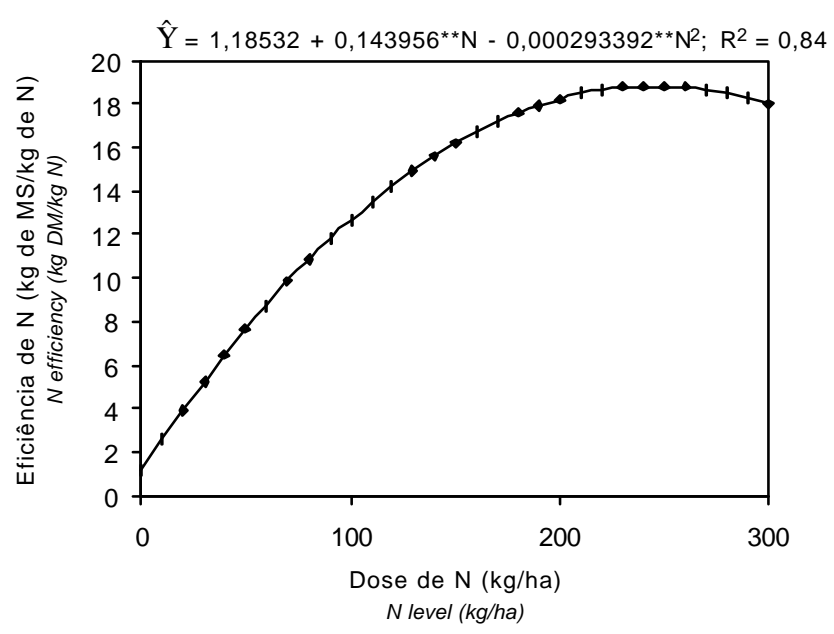

Figura 1 - Eficiência de utilização do nitrogênio por Brachiaria decumbens adubada com diferentes doses de $\mathrm{N}$.

Figure 1 - Nitrogen utilization efficiency by Brachiaria decumbens fertilized with different $N$ doses. 
Tabela 4 - Teor de PB (\% da MS) da folha e do colmo de Brachiaria decumbens (soma de três cortes) adubada com diferentes doses de fósforo e de nitrogênio

Table 4 - CP concentration (DM \%) (sum of three cuts) of leaf and stem of Brachiaria decumbens fertilized with different phosphorus and nitrogen doses

\begin{tabular}{lcccc}
\hline $\begin{array}{l}\text { Dose de } \mathrm{P}_{2} \mathrm{O}_{5}(\mathrm{~kg} / \mathrm{ha}) \\
\mathrm{P}_{2} \mathrm{O}_{5} \text { dose }(\mathrm{kg} / \mathrm{ha})\end{array}$ & $\begin{array}{c}\text { Dose de } \mathrm{N}(\mathrm{kg} / \mathrm{ha}) \\
N \text { dose }(\mathrm{kg} / \mathrm{ha})\end{array}$ & $\begin{array}{c}\text { Média } \\
\text { Mean }\end{array}$ & $\begin{array}{c}\text { Equação de regressão } \\
\text { Regression equation }\end{array}$ \\
\cline { 2 - 5 } & 100 & 200 & 300
\end{tabular}

\begin{tabular}{|c|c|c|c|c|c|c|}
\hline \multirow[b]{2}{*}{0} & \multicolumn{4}{|c|}{$\begin{array}{l}\text { Teor de PB da folha (\% da MS) } \\
\text { Leaf CP concentration (DM \%) }\end{array}$} & \multirow[b]{2}{*}{12,9} & \multirow{9}{*}{1} \\
\hline & 9,6 & 12,4 & 14,6 & 14,9 & & \\
\hline 50 & 9,6 & 12,5 & 13,7 & 15,1 & 12,7 & \\
\hline 100 & 9,6 & 12,3 & 14,2 & 14,6 & 12,7 & \\
\hline Média & 9,6 & 12,4 & 14,2 & 14,9 & & \\
\hline \multirow{4}{*}{$\begin{array}{l}\text { Mean } \\
\text { CV }(\%)\end{array}$} & & & & & & \\
\hline & 4,1 & & & & & \\
\hline & \multirow{2}{*}{\multicolumn{4}{|c|}{$\begin{array}{l}\text { Teor de PB do colmo (\% da MS) } \\
\text { Stem CP concentration (DM \%) }\end{array}$}} & & \\
\hline & & & & & & \\
\hline 0 & 6,1 & 6,8 & 8,3 & 8,3 & 7,4 & \\
\hline 50 & 5,9 & 6,9 & 7,8 & 8,8 & 7,4 & \\
\hline 100 & 5,8 & 7,0 & 8,0 & 9,1 & 7,5 & \\
\hline Média & 5,9 & 6,9 & 8,0 & 8,8 & & 2 \\
\hline \multicolumn{6}{|l|}{ Mean } & \\
\hline $\mathrm{CV}(\%)$ & 5,0 & & & & & \\
\hline
\end{tabular}

$1-\hat{Y}=9,5460918+0,033677669^{* *} X N-0,0000531193^{* *} x N^{2} ; R^{2}=0,99 ; 2-\hat{Y}=5,971702+0,009520^{* *} x N ; R^{2}=0,96$

$*{ }^{* *}(\mathrm{P}<0,05)$ e $(\mathrm{P}<0,01)$.

janeiro e março, respectivamente, com média de 7,6\% de PB. Dubeux Jr. et al. (1997) avaliaram pastagens de Brachiaria decumbens e verificaram valores de $7,9 \%$ de $\mathrm{PB}$ na parte aérea.

A eficiência de utilização do $\mathrm{N}$ sofreu efeito quadrático dos níveis de $\mathrm{N}(\mathrm{P}<0,05)$. Com o aumento das doses de fertilizantes, verificou-se aumento, com posterior redução na produção de MS por kg de N aplicado (Figura 1). O ponto de máxima foi atingido com $245,30 \mathrm{~kg}$ de $\mathrm{N}$, que correspondeu a $18,84 \mathrm{~kg}$ de MS/kg de N. Segundo Mazzanti et al. (1997), a resposta aparente do crescimento da planta forrageira depende de vários fatores, entre eles, a fonte de nitrogênio, as condições climáticas e do solo, o grau de fracionamento e a dose aplicada, o potencial de resposta da planta e a presença do animal.

Os valores da eficiência de utilização do nitrogênio foram de 12,65; 18,24 e 17,97 kg de MS/kg de N para as doses de 100, 200 e $300 \mathrm{~kg}$ de N/ha, respectivamente. A partir dos 245,30 kg de N/ha, houve redução da eficiência de utilização, o que difere dos valores descritos por Fagundes et al. (2005), que notaram diminuição da eficiência a partir de $75 \mathrm{~kg} /$ ha de $\mathrm{N}$, enquanto Heringer \& Moojen (2002) e Lupatini et al. (1998) encontraram também decréscimos a partir dos $150 \mathrm{~kg} / \mathrm{ha}$ de $\mathrm{N}$.

Para a dose de $245,3 \mathrm{~kg}$ de N/ha, referente ao ponto de máxima, houve aumento de 32,3 e 3,2\% na produção de MS, em comparação às doses de 100 e $200 \mathrm{~kg}$ de N/ha, e redução de 4,6\%, em comparação à dose de $300 \mathrm{~kg}$ de N/ha.

\section{Conclusões}

A aplicação de nitrogênio eleva a produção de MS de folhas e de colmos, proporcionando aumento na relação folha:colmo. Doses crescentes de fósforo não influenciaram a produção de MS da folha da Brachiaria decumbens. A adubação nitrogenada promove aumento na relação folha:colmo e melhora o valor nutritivo da forrageira. A eficiência de resposta à adubação com nitrogênio (kg de MS/kg de N) aumenta de acordo com as doses de $\mathrm{N}$ até atingir o nível de $245,30 \mathrm{~kg}$ de $\mathrm{N} / \mathrm{ha}$; a partir deste valor, a eficiência de utilização do nitrogênio pelo capimbraquiária diminui.

\section{Literatura Citada}

ANDRADE, J.B.; BENINTENDE, R.P.; FERRERI JR., E. et al. Efeito da adubação nitrogenada e potássica na produção e composição da forragem de Brachiaria ruziziensis. Pesquisa Agropecuária Brasileira, v.31, n.9, p.617-620, 1996.

AROEIRA, L.J.M.; PACIULlO, D.S.C.; LOPES, F.C.F. Disponibilidade, composição bromatológica e consumo de matéria seca em pastagem consorciada de Brachiaria decumbens com Stylosanthes guianensis. Pesquisa Agropecuária Brasileira, v.40, n.4, p.413-418, 2005.

BOTREL, M.A.; ALVIM, M.J.; FERREIRA, R.P. Potencial forrageiro de gramíneas em condições de baixas temperaturas e altitudes elevada. Pesquisa Agropecuária Brasileira, v.37, n.3, p.393-398, 2002.

BOtrel, M.A.; ALVIM, M.J.; XAVIER, D.F. Avaliação de gramíneas forrageiras na região sul de Minas Gerais. Pesquisa Agropecuária Brasileira, v.34, n.4, p.683-689, 1999. 
BRAZ, S.P.; NASCIMENTO JR., D.; CANTARUTTI, R.B. et al. Aspectos quantitativos do processo de reciclagem de nutrientes pelas fezes de bovinos sob pastejo em pastagem de Brachiaria decumbens na Zona da Mata de Minas Gerais. Revista Brasileira de Zootecnia, v.31, n.2, p.858-865, 2002.

CANTARUTTI, R.B.; ALVAREZ V, V.H.; RIBEIRO, A.C. Amostragem de solo. In: RIBEIRO, A.C.; GUIMARÃES, P.T.G.; ALVAREZ V, V.H. (Eds.) Recomendações para uso de corretivos e fertilizantes em Minas Gerais. 5a aproximação. Viçosa, MG: CFSEMG/UFV, 1999a. p.13-20.

CANTARUTTI, R.B.; MARTINS, C.E.; CARVALHO, M.M. et al. Pastagens. In: RIBEIRO, A.C.; GUIMARÃES, P.T.G.; ALVAREZ V, V.H. (Eds.) Recomendações para uso de corretivos e fertilizantes em Minas Gerais - $5^{\text {a }}$ aproximação. Viçosa, MG: CFSEMG/UFV. 1999b. p.332-341.

DEBEUX JR., J.C.B.; LIRA, M.A.; FREITAS, E.V. et al. Avaliação de pastagens de braquiárias na Zona-da-Mata de Pernambuco. Revista Brasileira de Zootecnia, v.26, n.4, p.659-666, 1997.

EUCLIDES, V.P.B.; EUCLIDES FILHO, K.; ARRUDA, Z.J. et al. Desempenho de novilhos em pastagens de Brachiaria decumbens submetidos a diferentes regimes alimentares. Revista Brasileira de Zootecnia, v.27, n.2, p.246-254, 1998.

FAGUNDES, J.L.; FONSECA, D.M.; GOMIDE, J.A. Acúmulo de forragem em pastos de Brachiaria decumbens adubados com nitrogênio. Pesquisa Agropecuária Brasileira, v.40, n.4, p.397-403, 2005.

FILGUEIRAS, E.P.; BORGES, A.L.C.C.; RODRIGUES, N.M. Efeito do período de vedação sobre a produção e qualidade da Brachiaria decumbens Stapf. I - matéria seca e proteína bruta. Arquivo Brasileiro de Medicina Veterinária e Zootecnia, v.49, n.5, p.587-601, 1997.

GOMIDE, J.A.; WENDLING, I.J.; BRAS, S.P. et al. Consumo e produção de leite de vacas mestiças em pastagem de Brachiaria decumbens manejadas sob duas ofertas diárias de forragem. Revista Brasileira de Zootecnia, v.30, n.4, p.1194-1199, 2001.

HERINGER, I.; MOOJEN, E.L. Potencial produtivo, alteração da estrutura e qualidade da pastagem de milheto submetida a diferentes níveis de nitrogênio. Revista Brasileira de Zootecnia, v.31, n.2, p.875-882, 2002

LUPATINI, G.C.; RESTLE, J.; CERETTA, M. et al. Avaliação da mistura de aveia preta e azevém sob pastejo submetido a níveis de nitrogênio. I - Produção e qualidade de forragem. Pesquisa Agropecuária Brasileira, v.33, n.11, p.1939-1943, 1998.

MAZZANTI, A.; MARINO, M.A.; LATTANZI, F. et al.Efecto de la fertilización nitrogenada sobre el crecimiento y la calidad del forraje de Avena e Raigrás anual en el sudeste Bonariense. Balcarce: INTA, 28p. 1997. (Boletim Técnico, 143).

PACIULLO, D.S.C.; AROEIRA, L.J.M.; ALVIM, M.J. et al. Características produtivas e qualitativas de pastagem de braquiária em monocultivo e consorciada com estilosantes. Pesquisa Agropecuária Brasileira, v.38, n.3, p.421-426, 2003.
PACIULLO, D.S.C.; GOMIDE, J.A.; QUEIROZ, D.S. et al. Composição química e digestibilidade in vitro de lâminas foliares e colmos de gramíneas forrageiras, em função do nível de inserção no perfilho, da idade e da estação de crescimento. Revista Brasileira de Zootecnia, v.30, n.3, p.964-974, 2001.

PACIULLO, D.S.C.; GOMIDE, J.A.; QUEIROZ, D.S. et al. Adubação nitrogenada do capim-elefante cv. Mott. 1. rendimento forrageiro e características morfofisiológicas ao atingir 80 e $120 \mathrm{~cm}$ de altura. Revista Brasileira de Zootecnia, v.27, n.6, p.1069-1075, 1998.

QUADROS, D.G.; RODRIGUES, L.R.A.; FAVORETTO, V. et al. Componentes da produção de forragem em pastagens dos capins Tanzânia e Mombaça adubados com quatro doses de NPK Revista Brasileira de Zootecnia, v.31, n.3, p.1333-1342, 2002.

RASSINI, J.B. Período de estacionalidade de produção de pastagens irrigadas. Pesquisa Agropecuária Brasileira, v.39, n.8, p.821-825, 2004

RIBEIRO JR., J.I. Análise estatística no SAEG. Viçosa, MG: Editora UFV, 2001. 301p.

RIBEIRO, K.G.; GOMIDE, J.A.; PACIULLO, D.S.C. Adubação nitrogenada do capim-elefante cv Mott. 2. valor nutritivo ao atingir 80 e $120 \mathrm{~cm}$ de altura. Revista Brasileira de Zootecnia, v.28, n.6, p.1194-1202, 1999.

ROSSI, C.; FAQUIN, V.; CURI, N. Calagem e fontes de fósforo na produção do braquiarão e níveis críticos de fósforo em amostras de Latossolo dos Campos das Vertentes (MG). Revista Brasileira de Zootecnia, v.26, n.6, p.1083-1089, 1997.

RUGGIERI, A.C.; FAVORETTO, V.; MALHEIROS, E.B. Efeito de níveis de nitrogênio e regimes de corte na distribuição, na composição bromatológica e na digestibilidade "in vitro" matéria seca de Brachiarai brizantha (Hochst) Stapf cv. Marandu. Revista Brasileira de Zootecnia, v.24, n.1, p.20-30, 1995 SARDA, P.O.; BORGES, A.L.C.C.; RODRIGUEZ, N.M. Taxa de lotação e manejo de pastagens de braquiária (Brachiaria decumbens) e soja perene (Neonotonia wightii). I - efeito sobre a disponibilidade de forragem e produção de proteína bruta das diferentes frações da planta. Arquivo Brasileiro de Medicina Veterinária e Zootecnia, v.50, n.3, p.293-301, 1998.

SILVA, D.J.; QUEROZ, A.C. Análise de alimentos (métodos químicos e biológicos). 3.ed. Viçosa, MG: Editora UFV, 2002. 235p.

YOKOYAMA, L.P.; VIANA FILHO, A.; BALBINO, L.C. et al. Avaliação econômica de técnicas de recuperação de pastagens. Pesquisa Agropecuária Brasileira, v.34, n.8, p.1335-1345, 1999.

ZIMMER, A.H.; EUCLIDES, V.P.B.; MACEDO, M.C.M. Manejo de plantas forrageiras do gênero Brachiaria. In: PEIXOTO, A.M.; MOURA, J.C.; FARIA, V.P. (Eds.) Plantas forrageiras de pastagens. Piracicaba: Fundação de Estudos Agrários Luiz de Queiroz, 1995. p.101-143.

Recebido: 20/2/2006 Aprovado: 10/4/2007 